\title{
BMJ Open Clinical handover in a bilingual setting: interpretative phenomenological analysis to exploring translanguaging practices for effective communication among hospital staff
}

Jack Pun (1)

To cite: Pun J. Clinical handover in a bilingual setting: interpretative phenomenological analysis to exploring translanguaging practices for effective communication among hospital staff. BMJ Open 2021;11:e046494. doi:10.1136/ bmjopen-2020-046494

- Prepublication history and additional supplemental material for this paper are available online. To view these files, please visit the journal online (http://dx.doi.org/10.1136/ bmjopen-2020-046494).

Received 02 November 2020 Accepted 21 August 2021
Check for updates

(C) Author(s) (or their employer(s)) 2021. Re-use permitted under CC BY-NC. No commercial re-use. See rights and permissions. Published by BMJ.

Department of English, City University of Hong Kong, Hong Kong, Hong Kong

Correspondence to Dr Jack Pun; jackpun@me.com

\section{ABSTRACT}

Objective To explore the linguistic features of translanguaging in bilingual handover practices and elicit the views of hospital staff on factors that hinder or facilitate effective handover practice in a bilingual environment.

Methods 78 hospital staff were recruited from hospital wards and emergency departments of two Hong Kong hospitals. They were interviewed to determine their perceptions of their handover communication in a bilingual context, and their responses were subjected to interpretative phenomenological analysis.

Results Based on the staff interviews, three dimensions with potential applications to effective clinical handover are identified. A revised Identify, Situation, Background, Assessment and Recommendation protocol accounting for linguistic pluralism (i.e., the translanguaging process) is suggested to underpin the future research agenda around effective clinical communication in a bilingual context. Conclusions Research on handover communication in multilingual contexts is limited. This study outlines linguistic pluralism at the handover stage and details the complexity of handover communication for staff in a bilingual context. It urges for more research with a specific focus on identifying avoidable linguistic issues that emerge from the clinical context and developing a suitable protocol to standardise staff's translanguaging processes to ensure a safe and efficient handover process in a bilingual environment.

\section{INTRODUCTION}

Handover is a pivotal, high-risk event in everyday hospital practice. Hospital staff transfer their responsibility and accountability for their patients to ensure continuity of care. One can argue that handover is the foremost recurring communicative event taking place between hospital staff across clinical disciplines and across the specific teams (e.g., doctors, nurses, allied health workers) providing patient care. Handover can be conducted in a range of clinical settings, including at the patient's bedside, at the
Strengths and limitations of this study

- Exploratory research to explore the linguistic features of translanguaging in bilingual handover practices.

- Interpretative phenomenological analysis to showcase hospital staff's personal lived experiences in bilingual medical handover.

- Filling the gap in the literature on handover communication in multilingual contexts.

- Limited generalisability of findings given the study sample.

- Limited reveal of specific causal relationships about the influences of nursing handover skills.

nursing station, in meeting rooms, during ward rounds and even in hospital corridors. Staff need to not only verbally communicate the patient's latest condition but also prepare written documentation with sufficient fluency to outline their decisions or plans. A growing amount of research ${ }^{1-4}$ has demonstrated an explicit link between the quality of handover communication and patient safety. In bilingual clinical contexts, where hospital staff need to operate between their first language and English as a lingua franca to communicate for clinical purposes, this may create a complicated process of 'code switching' or 'translanguaging' during clinical handover, which may be time-intensive, difficult to monitor and susceptible to errors. ${ }^{5}$

Code switching, according to Romaine, is defined as "the use of more than one language, variety or style by a speaker within an utterance or discourse, or between different interlocutors. ${ }^{6}$ In other words, code switching is the act of alternating between two or more languages in a single conversation. According to Garcia, translanguaging describes the way in which 
bilinguals or multilinguals discursively apply their linguistic and semiotic repertoires during the meaningmaking process. ${ }^{7}$ Translanguaging is generally a typical occurrence in the meaning-making process, wherein several linguistic and semiotic resources are drawn on and eventually arranged and summarised as a different language system. $^{8}$ Different from code switching, translanguaging involves the speakers' linguistic repertoire, which includes languages, dialects, ${ }^{9}$ words/ expressions in different languages, ${ }^{10}$ signs and emoticons to create a social space-a translanguaging spacein which speakers bring together dimensions of their experiences, histories and ideologies. ${ }^{11}$

Hong Kong has two official languages: Chinese (including the two spoken varieties of Cantonese and Putonghua, and standard written Chinese) and English. ${ }^{12}$ A majority of Hong Kong's population, more than seven million are native speakers of Cantonese. Cantonese hence remains the dominant vernacular cum lingua franca among Hong Kong citizens. While English is considered as a prestige language in many contexts, particularly in education, and is the main medium for university teaching in Hong Kong. Therefore, it is common for people in Hong Kong to code switch between the two languages. Meanwhile, the use of Putonghua is increasing, especially with an increasing number of nonCantonese Chinese visitors and residents. People with limited communication skills in the local languages may require an interpreter when attending important occasions such as hospital visits; the limited local language knowledge could lead to the inability to express themselves accurately and efficiently otherwise.

In the clinical environments in Hong Kong, with bilingual hospital staff, most members of staff are native speakers of Cantonese but received their medical training in English. Thus most likely they have little to no familiarity with medical terminology in Chinese. In everyday hospital routines, most hospital staff read and record nearly all of their medical records in written English, but communicate verbally with patients in Cantonese. In addition, doctors and nurses mostly code switch or engage in translanguaging with one another in spoken Cantonese mixed with medical English.

Despite an increasing number of studies in recent years focused on developing frameworks to promote effective clinical handover using standardised communication protocols, such as the Identify, Situation, Background, Assessment and Recommendation (ISBAR) protocol, ${ }^{13-16}$ where the ISBAR protocol is shown to be effective in structuring handover practices and in turn helps reduce instances of miscommunication and misunderstanding among hospital staff members. Translanguaging has not received much attention in medical communication. For instance, there is a clear lack of publications on the effects of translanguaging in medical handovers, with only Pun et $a l^{17}$ exploring the use of CARE protocol in a bilingual hospital context. This study, therefore, aims to contribute to the exploration of translanguaging practice in clinical handovers, and to develop a set of frameworks to enhance effective handover communication in a bilingual context.

\section{METHODS}

\section{Research design}

Interpretative phenomenological analysis (IPA) is a qualitative approach that investigates personal lived experiences within the field of psychology. ${ }^{18}$ As Smith and Osborn argued, personal experiences and detailed exploration of how individuals understand and make sense of them form the foundation of IPA. ${ }^{19}$ This approach to analysis assumes that one is continuously engaging actively with the world and reflecting on and integrating experiences. ${ }^{20}$ The investigation of experiences via IPA is understood as an allegorical analysis by both the participants and the researcher. To make sense of how the participants understand their world, both the researchers and the participants must be involved in a dual interpretation process called the 'double hermeneutic'. Researchers play an active role in determining how the participants are making sense of their world. ${ }^{20}$ Due to its seminal nature and capacity to investigate participants' complex lived experiences, IPA was selected as the analytical method for this study.

\section{Analysis}

This study adopted IPA, an idiographic approach that analyses a tightly defined group of participants who provide specific points of view in a particular area of study. The participants in this study were all experienced hospital staff who had been handling handover for more than 3 years in a bilingual hospital at the time of the study.

The research team comprised multidisciplinary experts $(\mathrm{M}=3, \mathrm{~F}=2)$, including two linguists $(\mathrm{PhD})$ who have extensive research experience in health communication, one physician (MD) from the Accident and Emergency Department, one professor $(\mathrm{PhD})$ in nursing and one nursing manager (PhD). To analyse the interview transcripts, the analytical stages suggested by Smith $e t$ al were followed.$^{20}$ Beginning with an individual focus and descriptive level, the analysis moved to a more mutual understanding of the clinical context at an interpretative level. The interview transcripts were read line by line, and notes on what was being said about handover were made as the initial researcher comments. Exploratory comments with the researchers' interpretations of the participants' use of language and communication issues during handover were then added to the transcript. By making these exploratory comments without referring to the content of other interview transcripts, the researchers were able to develop concise themes that echoed the participant's account. The techniques of subsumption and abstraction proposed by Smith $e t a l^{20}$ were adopted to determine patterns in the themes, which led to a series of superordinate themes for the participants.

\section{Data collection}

Hospital staff working in medical wards of a major tertiary hospital in Hong Kong were notified about the study and 
were recruited. Prospective candidates were invited by the Unit Managers via email. Verbal opt-in consent was obtained from all participants. No participants refused or dropped out from the study.

Observations of medical handovers and their corresponding audio recordings were collected. The researcher, one of the linguistics who specialises in health communication, then conducted semistructured face-toface interviews with the participants observed on their handover practices. Each interview lasted for approximately $30 \mathrm{~min}$. The interview tool presented in online supplemental appendix was adopted in this study, it first guided the participants to respond to some basic personal information then to more in-depth questions regarding clinical communication.

\section{Patient and public involvement}

No patient involved.

\section{RESULTS}

\section{Participant demographics}

A total of 78 hospital staff members were involved in the study, comprising 8 doctors and 70 nurses. The participants included doctor specialists, residents, nurse consultants, advanced practice nurses, registered nurses, enrolled nurses and hospital staff working at the management level. Sixty-three of the participants were younger than 35 , and 15 were above 35 . Their years of work experience in the emergency department, medical ward and surgical ward ranged from 2 years to more than 25 years for the doctors, and from 1 year to 23 years for the nurses. Table 1 provides the demographic and professional characteristics of the interviewees.

Findings were presented in three main themes, including (1) translanguaging processes in handover communication; (2) clinical communication issues in a multicultural speech community; and (3) communication issues at handover due to linguistic pluralism. The organisation of findings was based on the research team's understanding of clinical context presented in the transcripts using IPA.

\section{Translanguaging processes in handover communication}

Patient-clinician interactions are generally conducted in Cantonese, and occasionally in Putonghua or English. Patient information and subsequent medical procedures and diagnosis are recorded in the patients' files in written English. Clinicians communicate patient information between themselves using written English and (less frequently) spoken Cantonese with some English. The result is a continuous process of translation of medical information from Cantonese to English and then back again, as a patient's diagnosis and treatment-negotiated between clinicians in English-is usually conveyed back to the patient in Cantonese. As one senior doctor described, the bilingual nature of Hong Kong hospital work can be understood in terms of 'two parts. One is you
Table 1 Demographic background of the 78 interviewees

\begin{tabular}{|c|c|c|c|}
\hline & Doctors & Nurses & Total \\
\hline Amount & 8 & 70 & 78 \\
\hline \multicolumn{4}{|l|}{ Gender } \\
\hline Male & 8 & 7 & 15 \\
\hline Female & 0 & 63 & 63 \\
\hline \multicolumn{4}{|l|}{ Age } \\
\hline Under 35 & 4 & 59 & 63 \\
\hline Above 35 & 4 & 11 & 15 \\
\hline
\end{tabular}

Education

\begin{tabular}{|llll|}
\hline Diploma & 0 & 19 & 19 \\
\hline Bachelor's & 0 & 40 & 40 \\
\hline Master's or higher & 8 & 11 & 19 \\
\hline
\end{tabular}

Position

\begin{tabular}{llcr} 
Doctor specialist & 2 & NA & 2 \\
\hline Residents & 4 & NA & 4 \\
Management & 2 & NA & 2 \\
$\begin{array}{l}\text { Nurse consultant/ward } \\
\text { manager }\end{array}$ & NA & 2 & 2 \\
Advanced practice nurse & NA & 1 & 1 \\
Registered nurse & NA & 52 & 52 \\
Enrolled nurse & NA & 15 & 15 \\
Work experience & & & \\
$0-1$ & 0 & 6 & 6 \\
$2-5$ & 4 & 26 & 30 \\
$6-10$ & 0 & 22 & 22 \\
$>10$ & 4 & 16 & 20 \\
\hline
\end{tabular}

NA, not available.

get the history from [the] patient in Cantonese and then you need to write in English. The second part is we learn in English, we tell the patient in Cantonese...'.

As mentioned, the ISBAR protocol is used to better structure handover practices. Effective handover also requires understanding and evaluation of communicative practices at handover, perceptions of the hospital staff's own interactions, and other factors that staff may encounter in a bilingual context. Despite using a systematic framework, the communication flow among bilingual hospital staff appears to be complicated due to the use of two languages in both verbal and written forms. Such bilingual clinical interactions may be vulnerable to the loss of information or mistranslation if the involved stakeholders do not possess high proficiency in both languages in speaking and writing. This sociolinguistic context of the communication of information in the hospital is depicted in figure $1 .^{5}$ (1) The outgoing hospital staff members first verbally introduce the patient in Cantonese to the incoming team. (2) The incoming staff are provided with a written record in English for the patient. (3) The patient's situation and medical or personal needs are then 


\section{Introduction}
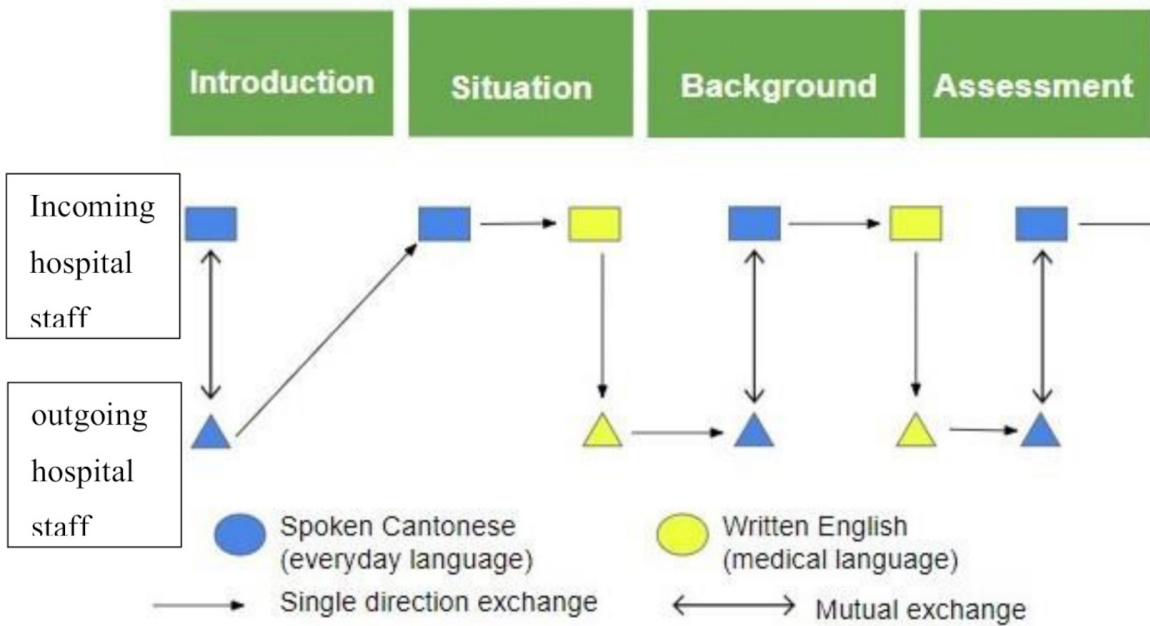

Figure 1 Translanguaging practice at handover.

clarified by the outgoing hospital staff. (4) Both incoming and outgoing teams verify the details and ask questions to avoid misunderstanding.

To illustrate the translanguaging process and the potential issues deriving from clinical handover, figures 2 and 3 below are representative of the collected samples of handover communication, all names are reidentified and presented as pseudonyms for the anonymity of the participants. These two examples are verbatim transcriptions of clinical handovers for the same patient on two separate days by two different nursing teams.

Several issues are noted in text 1 , which demonstrates a lack of interaction and patient identification. At no time did the outgoing nurse mention the patient's background information, such as age, bed number, medical history or other relevant documentation, for the incoming team's reference. The information provided in some stages was vague and indirect. For instance, in stage 7 , the instructions were ambiguous. It is not evident whether the incoming nurse needed to note when and how often blood samples should be taken from the patient. Also, the object in stage 7 appeared to be missing in such translanguaging utterance, as seen in 'in V shape'; the exact position for blood taking might be unclear to recipient and hence, causing potential deficits in the clinical interaction.

Additionally, there was no logical sequence in this handover communication. Recommendations for future care tasks were spread throughout the handover instead of being listed together in the final stage. Nor did the outgoing nurse ask for a readback of the key tasks, and the incoming team had no questions and made no effort to confirm and double-check the information. Such a lack of interaction may be problematic, as both parties are not clear about the other's degree of information, which may cause misunderstandings and ultimately affect the patient.

Compared with the text in figure 2, the text in figure 3 is more complete and more comprehensive. The outgoing nurse started the handover process by providing detailed background information, such as the patient's age, medical history and medication allergies. Similarly, translanguaging was involved in such utterances. Meanwhile, the handover in figure 3 appeared to be clearer and more structured despite the use of two languages. In stage 6 , all of the medical jargon were expressed in an English verbal form, 'total mastectomy' for instance. Given the English medical training and familiarity with technical terminology in English, the incoming nurse might in fact perceive such bilingual communication to be easier to comprehend.

The information was also presented in a more logical sequence, starting with a background, followed by an assessment and finally recommendations. Recommendations were made at the end of the handover along with explicit instructions. With straightforward instructions such as 'you don't have to...' and 'please help the patient', the incoming nurses had a clear idea of what they were supposed to do.

Although the handover communication in figure 3 presented a full picture of the information to which the incoming nurses should attend, there was still minimal feedback from the incoming team and no clear indication of whether they have retained the message and acknowledged the transfer of responsibility. Moreover, as there was no mention of any written documentation, it is unclear whether the verbal handover was the only source of communication or if written records also played a role in the handover.

\section{Clinical communication issues in a multicultural speech community} Communicating with patients from diverse linguistic backgrounds Many interviewees noted the challenge of effectively communicating with the increasing migrant population attending the hospital, who have limited Cantonese and English communication skills. This was specifically stressed as one of the major communication hurdles in triage, with one nurse reflecting that at times it posed safety issues for patients who are unable to communicate the nature of their illness. 
Text 1: 22041 Day 1

\begin{tabular}{|c|c|c|}
\hline \# & Transcript of the outgoing nurse's talk & iSBAR stage \\
\hline & & Identification: patient \\
\hline 1 & $\begin{array}{l}\text { 曹醫生外遊，宋醫生陪代。 } \\
\text { Dr Cho is on vacation. Dr Sung will be in charge. }\end{array}$ & Identification: doctors \\
\hline 2 & $\begin{array}{l}\text { CA right breast } \\
\text { The patient is diagnosed with CA on right breast, }\end{array}$ & $\begin{array}{l}\begin{array}{l}\text { Situation: presenting } \\
\text { condition }\end{array} \\
\end{array}$ \\
\hline 3 & $\begin{array}{l}\text { Right skin sparing total mastectomy and frozen section and sentinel } \\
\text { lymph node biopsy and left nipple-sparing total mastectomy and } \\
\text { bilateral TRAM flap reconstruction. } \\
\text { She had a right skin sparing total mastectomy and frozen section and } \\
\text { sentinel lymph node biopsy and left nipple-sparing total mastectomy } \\
\text { and bilateral TRAM flap reconstruction on the } 29^{\text {th }} \text {. }\end{array}$ & Situation: surgery \\
\hline 4 & $\begin{array}{l}\text { 病人雙乳房同埋塆部腹部傷口痛少, pain score } 1 \text { 分, 無滲血。 } \\
\text { The patient reported slight pain in both her breast, naval and } \\
\text { abdominal wounds. Pain score is } 1 \text {, no blood ooze. }\end{array}$ & Assessment: wound \\
\hline 5 & $\begin{array}{l}\text { 之前話頭量，但今日起身食返野落孀地就 ok. } \\
\text { She reported dizziness yesterday, but today she is able to leave her } \\
\text { bed and eat. }\end{array}$ & Assessment: general \\
\hline 6 & $\begin{array}{l}\text { 有個 TED stocking on 住，不過已經叫咗佢除，因為佢已經可以 } \\
\text { 自己落皭床 } \\
\text { She is on TED stockings, but we have already instructed her to } \\
\text { remove them since she is able to leave her bed without assistance. }\end{array}$ & Assessment: mobility \\
\hline 7 & $\begin{array}{l}\text { 雙手禁量血厴咁抽血，keep 返 V Shape 返上床就 head up } \\
\text { abdominal down, knee up. } \\
\text { The position for blood taking should be done similarly to measuring } \\
\text { blood pressure, in a V shape, and then when the patient is in bed, } \\
\text { head up, abdominal down, knee up. }\end{array}$ & Recommendation \\
\hline 8 & $\begin{array}{l}\text { BCC 帶就睇咗隻飲食，謢理咽度就未睇。 } \\
\text { BCC has set the diet arrangement, but nursing care has not met the } \\
\text { patient yet. }\end{array}$ & \\
\hline 9 & $\begin{array}{l}\text { 係床喵度要放高隻腳，用一個枕頭嘅。 } \\
\text { We have set her legs on a pillow in bed. }\end{array}$ & Assessment \\
\hline 10 & 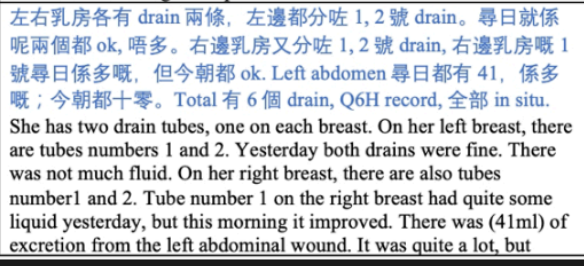 & $\begin{array}{l}\text { Assessment: } \\
\text { observations }\end{array}$ \\
\hline \multirow[t]{2}{*}{ \# } & Transcript of the outgoing nurse's talk & iSBAR stage \\
\hline & $\begin{array}{l}\text { today it has decreased to about } 10 \mathrm{ml} \text {. There is a total of } 6 \text { drain } \\
\text { tubes. Related records should be kept every } 6 \text { hours. They are } \\
\text { currently all (in situation) }\end{array}$ & \\
\hline 11 & $\begin{array}{l}\text { Q6H record, 全部 in situ. } \\
\text { related records should be kept every } 6 \text { hours, they are currently all in } \\
\text { situation. }\end{array}$ & Recommendation \\
\hline 12 & $\begin{array}{l}\text { Follow up 曹醫生呢個 case 係 } 9 \text { 樓 BCC 咱度見佢, 出院咱時要 } \\
\text { 幫佢 book 埋。 } \\
\text { Dr Cho will follow up the case, the appointment will be conducted } \\
\text { in the BCC department on } 9^{\text {th }} \text { floor. We should book the } \\
\text { appointment for the patient when she is discharged from the } \\
\text { hospital. }\end{array}$ & Recommendation \\
\hline 13 & $\begin{array}{l}\text { 申訴大便困難，??? } 10 \mathrm{ml} \text { BD PO 乘 } 2 \text { 日， } 1300 \text { 開始俾咗佢食 } \\
\text { She reported constipation. A prescription of (drug name) } 10 \mathrm{ml} \text { has } \\
\text { been issued for } 2 \text { days, twice a day. The patient was medicated at } \\
1300 \text {. }\end{array}$ & $\begin{array}{l}\text { Assessment: } \\
\text { medication }\end{array}$ \\
\hline & & Readback \\
\hline
\end{tabular}

Figure 2 Transcript of handover communication sample 1. ISBAR, Identify, Situation, Background, Assessment and Recommendation. Note: $\mathrm{CA}=$ cancer and carcinoma; TRAM $=$ transverse rectus abdominis; $\mathrm{BCC}=$ Breast Care Centre

If they're in [an] emergency situation, they need urgent care and urgent treatment, but we delay it [because] of the language barrier. Nurse Specialist,

Interview 4

Interpreter services in the medical field remain a relatively new concept. ${ }^{21}$ While this service is provided in the hospital, interpreters are not immediately available to the medical teams, who, as discussed above, work in a context wherein assessing patient needs within a very limited time frame is considered essential to ensure both patient safety and the organisational flow of the hospital. When asked what measures they adopt in situations when no translator is available, a few interviewees explained that they greatly simplify their language and when this failed, rely on physical cues. One

\section{Text 2: 22041 Day 2}

\begin{tabular}{|c|c|c|}
\hline \# & Transcript of the outgoing nurse's talk & iSBAR stage \\
\hline 1 & $\begin{array}{l}\text { CA right breast, } 51 \text { 数女士, } 6 \text { 月 } 28 \text { 日入院 } \\
\text { A } 51 \text {-year-old lady who is suffering from right breast cancer, who } \\
\text { was admitted to our hospital on } 28 \text { June and bed number } 22041 \\
\text { was assigned to her. }\end{array}$ & $\begin{array}{l}\text { Identification: patient } \\
\text { Situation: presenting } \\
\text { condition }\end{array}$ \\
\hline 2 & 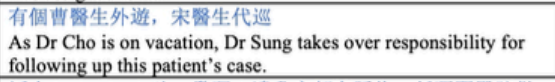 & Identification: doctors \\
\hline 3 & 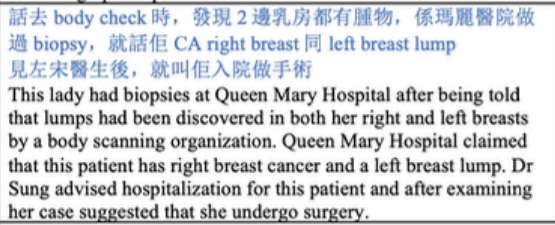 & Background: history \\
\hline 4 & $\begin{array}{l}\text { The patient is allergic to tegaderm - if she consumes tegaderm, } \\
\text { she will develop a skin rash. }\end{array}$ & Background: alerts \\
\hline 5 & 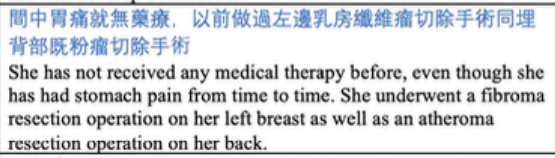 & Background: surgical \\
\hline 6 & $\begin{array}{l}\text { 呢個病人最新 } 6 \text { 月 } 29 \text { 日做左 right skin sparing, total } \\
\text { mastectomy, frozen section, sentinel node biopsy, left nipple } \\
\text { sparing, total mastectomy? , bilateral tram flap Reconstruction } \\
\text { The latest operations that the patient underwent on } 29 \text { June are } \\
\text { right skin sparing total mastectomy, frozen section, sentinel node } \\
\text { biopsy, left nipple sparing total mastectomy and bilateral trim flap } \\
\text { reconstruction. }\end{array}$ & Situation: surgery \\
\hline 7 & $\begin{array}{l}\text { 今日就精神普通呼吸順 } \\
\text { The patient is stable with a normal respiration and mental state. }\end{array}$ & Assessment: general \\
\hline 8 & $\begin{array}{l}\text { The wounds on both the breasts and abdomen are still a little bit } \\
\text { painful with a pain score of } 2 \text {. Fortunately, the wounds are not } \\
\text { bleeding. }\end{array}$ & Assessment: wound \\
\hline 9 & $\begin{array}{l}\text { 之前又話過頭最，今日都無 } \\
\text { She felt dizzy yesterday but today she feels good. }\end{array}$ & Assessment: general \\
\hline \# & Transcript of the outgoing nurse's talk & iSBAR stage \\
\hline 10 & 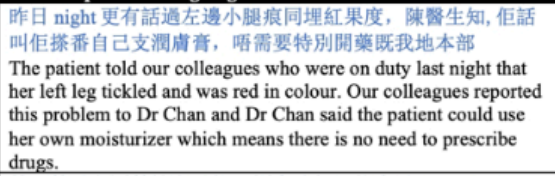 & Assessment: specific \\
\hline 11 & $\begin{array}{l}\text { 雙手禁量血原禁抽血, 如果訓床時侯, 就盡量要 head up 同埋 } \\
\text { abdomen gown? Knee up, V-shape 咁椂 } \\
\text { The condition of the patient does not allow us to take her blood } \\
\text { pressure or take blood samples. The patient should raise her head } \\
\text { and knees in a V-shape when she lies down on the bed. }\end{array}$ & Assessment: specific \\
\hline 12 & $\begin{array}{l}\text { 不過佢而家都自己落黎行路 } \\
\text { But actually, she has now started leaving her bed and having a } \\
\text { walk. }\end{array}$ & Assessment: mobility \\
\hline 13 & $\begin{array}{l}\text { BCC (Breast Care Centre) 果度已經睇完 } \\
\text { [She] has already visited the Breast Care Centre. }\end{array}$ & \\
\hline 14 & $\begin{array}{l}\text { 咁就要 elevate 倜大脾 with } 1 \text { 個 pillow, 如果訓床時, 都有施 } \\
\text { 行, 而家落床就嘌需要 } \\
\text { We have been instructed to put a pillow under the patient's thighs } \\
\text { if she is in bed. As the patient is not in bed now, you don't have to } \\
\text { do so. }\end{array}$ & Recommendation \\
\hline 15 & 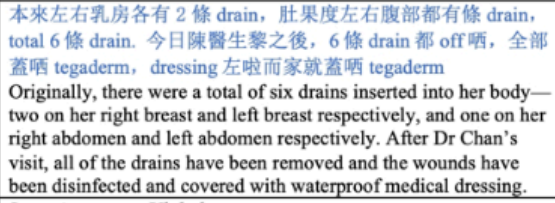 & $\begin{array}{l}\text { Assessment: } \\
\text { observations }\end{array}$ \\
\hline 16 & Incoming nurse: Uh huh & \\
\hline 17 & $\begin{array}{l}\text { plan 佢㱍日會出院 } \\
\text { We plan to let the patient leave our hospital tomorrow. }\end{array}$ & $\begin{array}{l}\text { Recommendation - } \\
\text { discharge }\end{array}$ \\
\hline 18 & 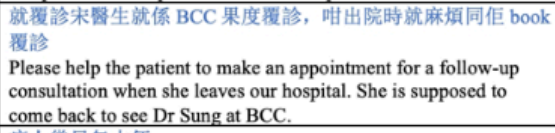 & Recommendation \\
\hline 19 & $\begin{array}{l}\text { 病人幾日無大便 } \\
\text { The patient has been suffering from constipation for several days. }\end{array}$ & \\
\hline 20 & Incoming nurse: Uh huh & \\
\hline
\end{tabular}

Figure 3 Transcript of handover communication sample 2. ISBAR, Identify, Situation, Background, Assessment and Recommendation. Note: $\mathrm{BCC}=$ Breast Care Centre

nurse explained that she sometimes sought help from security staff on the same shift, who might share the same country of origin as the presenting patient. 
Now sometimes I'll see if there's any security [staff] ...of that particular nationality. Sometimes they can give us a hand. Right. We had that before. Now if that doesn't work out...Sometimes...when we want to solve things ASAP, it's through body language and stuff.

\section{Registered Nurse, Interview 23}

For one doctor, the presence of a translator, while necessary, interrupted the one-on-one relationship between doctor and patient and posed a risk of information loss through the intervention of a third party.

...for patient[s] who come from, e.g. Nepal, or the Africa...their English level may not be so... good to present what they want. But they usually come with a translator. They bring their OWN translator. Maybe sometime $[\mathrm{s}]$...we contact the translator through the phone... But actually there's the problem of the doctor to-there's no direct doctor-patient relationship, because there is the translator; we need the translator. There may be some information missed during the translation.

Interview 19, Doctor

\section{Communicating with patients from diverse societal groups}

The nurse interviewees reported similar communication difficulties with elderly patients, who would often arrive at the hospital with escorts who were unfamiliar with their medical condition or even the sequence of events that had led to their arrival at the hospital.

Lots of the time ...elderly [patients] have problems with speaking and listening... and they may not be able to process what we asked about. And the problem is a lot of them who accompany the patients are just staff [from the] out-patient visit escort service. They know absolutely nothing about the elderly. They just count on a...note to tell us how they're feeling unwell. But actually [in terms of] how long, and any sort of details, they know nothing... Have they taken Panadol? They don't know.

In situations where triage nurses felt particularly unsure about a patient's condition due to the patient's inability to convey the precise nature of their complaint, they adopted a policy of triaging up. This appeared to be a department-wide policy in situations where triage nurses felt unsure about the urgency of a patient's presenting conditions, as opposed to any individual nurse's strategy.

We don't want to sacrifice our patient...If we don't know, or we do not have a very clear history, we will [in] triage upgrade the patient, rather than downgrade the patient. It is for the patient's sake....all our staff will try to do this.

\section{Senior Nurse, Interview 5}

The resources that clinicians drew on to adequately provide patients with the emergency care they desired and deserved are discussed in the following section. There we discuss the interactional themes that emerged in our analysis; that is, how clinicians perceived that they developed empathy and rapport with their patients.

We now turn to another key theme that emerged in relation to the transfer of information across the hospital, namely the challenges staff face in communicating patient information and treatment across languages-something unique to the multilingual Hong Kong context.

\section{Communication issues due to linguistic pluralism}

\section{Information change or loss}

The interview respondents were slightly more likely to report a potential information loss or change in the translation of English medical knowledge into spoken Cantonese when communicating with patients $(48 \%)$ than when translating patient-provided information in Cantonese into written English medical records (45\%). In the interviews, although clinicians acknowledged the difficulty in communicating English medical diagnoses to patients, where they often reflected that at times there were simply no corresponding Cantonese terms. They also expressed challenges in translating the patient's history in medical records.

Translating from English to Chinese, yes, there are sometimes problems. We give it our best. It may not be really exactly that term, because even if we translate that into Chinese, s/he [the patient] wouldn't understand, [the] only thing we can do is put it more literally, describe the situation. While writing up the medical records can sometimes be challenging, too, because we have to think about the terminology in English corresponding to the patient's condition.

\section{Resident, Interview 20}

Where Cantonese terms could not be readily translated into English (which was generally reported as occurring in the translation of Chinese medical terminology), Chinese terms were readily incorporated into patient files. This could be a problem, however, when the electronic record system was used.

... most of the time, translation [isn't] a problem, UNLESS some situation where, say, drug overdose or [the patient] has taken some, say, Chinese medicine... And this thing, first, may not have a [corresponding] English [term]. Second, even...in the CMS entry, you may not even find such an entry for you to enter it; Chinese medicine may not be put in. So this is, for NOW and the future, a challenge for documentation.

Senior doctor, Interview 9

\section{Diverse modes of communication at handover}

Handover practices, or how, what and when patient information is passed on between clinicians over the course of a patient's treatment, were described by many interviewees as less than ideal, due to time pressure and 
the other organisational constraints mentioned above. While written notes were the most frequent mode of handover communication. Considering the use of multiple languages, concise message transfer might be achieved more easily through written than oral communication. Since translanguaging is often involved in verbal communication, additional effort might be required for clarification and checking for understanding in order to minimise the risks of miscommunication. Some interviewees reported that there was no fixed method for handing over patient information, meanwhile, face-toface handover was still considered to be the preferred method when and if time is allowed by one doctor interviewee given the thorough information obtained.

We try our best to... handover person to person... Sometimes if it isn't doable, then perhaps ...I'd write down the impression I have of a patient; actually why I have to handover because, firstly, for what investigation I'm waiting for. Say, this patient is waiting to have an X-ray done for his/her lungs, if the lungs turn out to be normal, then perhaps s/he can go. If it's pneumonia, then perhaps s/he has to be admitted. Things like that. And we can follow up on that better.

Medical specialist, Interview 9

Any face-to-face handover was normally conducted between nurses and nurses or doctors and doctors; handover between nurses and doctors was regarded as exceptional by interviewees in both professions. To facilitate efficient handover practices, professionals generally preferred communicating within the same discipline because of the time constraints. Language use may also play a part, however, since slight variations in the use of languages for certain expressions across disciplines may discourage cross-disciplinary handover in order to prevent potential inefficiencies and miscommunications. Interdisciplinary communication in this sense was therefore portrayed as impractical in a bilingual hospital such as in the context of emergency department.

...Because of our case load in Hong Kong...it seems to be not practical. Because for example if you want to have a handover, you may spend at least 15 to 20 minutes; but patients still keep coming in! You can't stop your service and explain in detail for the handover...so it is practically very difficult for us to do a formal handover between doctors and nurses. So we just do some, mini-handovers between the doctors themselves, and the nurses, they will also do some handovers amongst themselves.

\section{D2, Senior doctor, Interview 1}

\section{Incidents or risks accounted for in communication problems}

Translanguaging of clinical handover communication might be more susceptible to clinical staff who might misinterpret information due to the frequent switches in language. Thirty-three per cent of the interview respondents reported the possibility of adverse incidents occurring due to communication problems during handover, particularly in the bilingual clinical contexts.

Written patient records appeared to be an essential medium for information exchange between nursing and medical staff. Interestingly, however, several interviewees commented that given the routine nature of emergency care, medical records were seen as complementary-not compulsory-resources for delivering patient treatment:

This is not really about what you read [in the medical notes]; this is... pattern recognition. Same as treating patients. [When] you read the notes, you're not reading each and every word. Rather, you EXPECT what $\mathrm{s} /$ he's going to write. I mean, then we use the pattern to match things up, "eh? This looks like, say, abrasion on the right hand and such", or this is a laceration on the left hand. I mean, this is the way things go. Such is the departure point to read notes, actually it's easier to read.

Senior doctor, Interview 9

\section{Discussion}

In a bilingual clinical context, hospital staff consistently operate between their first language and medical English. From the interview, our participants reported that information change or loss could occur when communicating between spoken Chinese and written English medical records.

The hospital staff used Cantonese as the primary medium of communication for explaining patients' diagnoses and latest conditions, but when they performed a clinical handover with other staff, they tended to code switch between English medical terms and Cantonese as a supplementary language. Both doctors and nurses tended to use Cantonese as the matrix language, embedded with English technical terms.

As illustrated by the hospital staff interview data, a senior doctor said, 'detailed information is lost during translation process especially from English to Cantonese'. Another doctor said, 'Difficulty to describe details in English about the story why a patient fell down [when reporting back to senior management]'.

Such translanguaging processes at clinical handover may create two translation problems: (1) a gap between medical terms and everyday language; and (2) a gap between the spoken Cantonese explanation and spoken English terms. This two-part translanguaging process may lead to a loss of information or an increase in confusion.

A nurse said, 'if we come across English [terms] that we really don't know about but need to put down in record, there's no problem with writing in Chinese. Even drawing works...'

The factor of multicultural speech community could exacerbate such translation problems. Given the unfamiliarity of local languages, non-local patients might experience difficulties expressing themselves accurately and effectively in the medical settings. Healthcare professionals might also encounter more obstacles when 
attempting to deliver quality medical services given the diverse linguistic and societal backgrounds of patients.

A nurse specialist explained, 'but we delay it [because] of the language barrier...'

Miscommunication and communication breakdowns between clinicians and patients and between clinicians themselves continue to be identified as leading causes of both critical incidents in Hong Kong hospitals and overall patient dissatisfaction. ${ }^{22} 23$

For handovers in a bilingual context, the hospital staff shared certain conventional approaches. The nurses did not consistently follow a predictable structure, and each staff member handed over in their own way. Some structured their information in a relatively logical sequence, whereas others did not. In some cases, information was presented in an apparently arbitrary order. The consequences of the lack of a consistent and logical structure included the following. (1) Outgoing nurses sometimes did not provide information that incoming nurses needed or would have expected to learn during handover; (2) information was sometimes confusing, incomplete or ambiguous; (3) the conclusion of the handover often appeared arbitrary; and (4) actions required for the patient's ongoing care were not clearly stated. This meant that outgoing nurses left the handover with no clear idea of whether the incoming nurses had clearly heard, understood and retained the information about the patient and-most importantly-the instructions for ongoing care. The incoming team members did not double-check or question ambiguous information, nor did they probe to elicit missing information. A clear summary and explicit understanding of ensuing care for each patient need to be agreed on during the handover, even if the incoming nurse conducts a patient round after the handover.

Hospital should equip staff with communication protocols for effective handover communication in a bilingual context. One way is to encourage staff to follow the iSBAR structure when delivering their verbal handover, especially in situations where they need to engage in translanguaging between different languages, such as Cantonese and English, and everyday language and medical language. Following the iSBAR protocol (as illustrated in figure 1) for verbal delivery has many advantages. First, it ensures that all hospital staff share the same expectations of the information they should hear in sequence at a bilingual handover, and can ask questions or check for missing or confusing information at the appropriate point. This makes the handover efficient and systematic, eliminating irrelevant interruptions. Second, it ensures that hospital staff arrive at the 'recommendations and readback' stage, during which they make explicit what the incoming team must do on the next shift.

This study has some limitations. First, the participants were hospital staff from bilingual hospitals in Hong Kong; therefore, the findings should be generalised with caution. Second, though the results provide meaningful insights into clinical communication in a bilingual setting, the collected data were still limited in revealing specific causal relationships. Further research is thus warranted to explore more factors that may influence the effects of training on nurses' handover skills.

\section{Conclusion}

This study focused on hospital staff working in a bilingual context to investigate the linguistic features of translanguaging during handover communication. Hospital staff in a bilingual environment are required to communicate during handovers in both English and their first language, such as Cantonese in Hong Kong. This paper also elicited their views about factors that hinder or facilitate effective handover practice when operating in different languages (i.e., Cantonese and English, everyday and medical language). For effective clinical handover in a bilingual context, training programmes should be developed to improve the ability of bilingual staff to share updated patient care plans and their ability to grasp patient information. This can largely reduce avoidable communication failures due to the translanguaging process when staff need to consistently switch between medical language (English) and everyday language (Cantonese). Moreover, handovers would be safer and more consistent if hospital staff agreed on and followed a systematic structure to present their handover information. This paper recommends training hospital staff to incorporate iSBAR into both the verbal and written dimensions of the handover. An agreed-upon structure ensures that hospital staff cover all required minimum information in a concise and predictable sequence.

Contributors The author designed the research, performed data collection and analysis, and wrote the paper.

Funding The authors have not declared a specific grant for this research from any funding agency in the public, commercial or not-for-profit sectors.

Competing interests None declared.

Patient consent for publication Not applicable.

Ethics approval This study was approved by the Hong Kong Polytechnic University Human Research Ethics Committee (HREC) and the hospital HREC (Ethics ID number: RC-2017-07).

Provenance and peer review Not commissioned; externally peer reviewed.

Data availability statement Data sharing not applicable as no datasets generated and/or analysed for this study. No data are available.

Supplemental material This content has been supplied by the author(s). It has not been vetted by BMJ Publishing Group Limited (BMJ) and may not have been peer-reviewed. Any opinions or recommendations discussed are solely those of the author(s) and are not endorsed by BMJ. BMJ disclaims all liability and responsibility arising from any reliance placed on the content. Where the content includes any translated material, BMJ does not warrant the accuracy and reliability of the translations (including but not limited to local regulations, clinical guidelines, terminology, drug names and drug dosages), and is not responsible for any error and/or omissions arising from translation and adaptation or otherwise.

Open access This is an open access article distributed in accordance with the Creative Commons Attribution Non Commercial (CC BY-NC 4.0) license, which permits others to distribute, remix, adapt, build upon this work non-commercially, and license their derivative works on different terms, provided the original work is properly cited, appropriate credit is given, any changes made indicated, and the use is non-commercial. See: http://creativecommons.org/licenses/by-nc/4.0/.

ORCID iD

Jack Pun http://orcid.org/0000-0002-8043-7645 


\section{REFERENCES}

1 Eggins S, Slade D. Communication in clinical handover: improving the safety and quality of the patient experience. J Public Health Res 2015;4:666.

2 Merten H, van Galen LS, Wagner C. Safe handover. BMJ 2017;359:j4328.

3 Bukoh MX, Siah C-JR. A systematic review on the structured handover interventions between nurses in improving patient safety outcomes. J Nurs Manag 2020;28:744-55.

4 Burgener AM. Enhancing communication to improve patient safety and to increase patient satisfaction. Health Care Manag 2020;39:128-32.

5 Pun JKH, Matthiessen CMIM, Murray KA, et al. Factors affecting communication in emergency departments: doctors and nurses' perceptions of communication in a trilingual ED in Hong Kong. Int $J$ Emerg Med 2015;8:48.

6 Romaine S, Algeo J, Lass R. The Cambridge history of the English language. . Cambridge University Press, 1992: Vol 3. 100.

7 García O. Emergent Bilinguals and TESOL: What's in a Name? TESOL Quarterly 2009;43:322-6.

8 Lin AMY, He P. Translanguaging as dynamic activity flows in CLIL classrooms. J Lang Identity Educ 2017;16:228-44.

9 Busch B. The linguistic repertoire revisited. Appl Linguist 2012;33:503-23.

10 Jørgensen JN. Polylingual Languaging around and among children and adolescents. Int $J$ Multiling 2008;5:161-76.

11 Wei L. Moment analysis and translanguaging space: Discursive construction of identities by multilingual Chinese youth in Britain. $J$ Pragmat 2011;43:1222-35.

12 Evans S. Language in transitional Hong Kong: perspectives from the public and private sectors. J Multiling Multicult Dev 2010;31:347-63.
13 Finnigan MA, Marshall SD, Flanagan BT. ISBAR for clear communication: one hospital's experience spreading the message. Aust Health Rev 2010;34:400-4.

14 Flemming $\mathrm{D}$, Hübner U. How to improve change of shift handovers and collaborative grounding and what role does the electronic patient record system play? Results of a systematic literature review. Int J Med Inform 2013;82:580-92.

15 Kitney P, Tam R, Bennett P, et al. Handover between anaesthetists and post-anaesthetic care unit nursing staff using ISBAR principles: a quality improvement study. ACORN: The Journal of Perioperative Nursing in Australia 2016;29:30-5.

16 Robertson ER, Morgan L, Bird S, et al. Interventions employed to improve intrahospital handover: a systematic review. BMJ Qual Saf 2014;23:1-8.

17 Pun J, Chan EA, Man M, et al. Pre- and post evaluations of the effects of the Connect, Ask, Respond and Empathise (CARE) protocol on nursing handover: A case study of a bilingual hospital in Hong Kong. J Clin Nurs 2019;28:3001-11.

18 Smith JA. Beyond the divide between cognition and discourse: using interpretative phenomenological analysis in health psychology. Psychol Health 1996;11:261-71.

19 Smith JA, Osborn M. Interpretative phenomenological analysis. In: Qualitative psychology: a practical guide to research methods, 2008: 53-80.

20 Smith JA, Flowers P, Osborn M. Interpretative phenomenological analysis and the psychology of health and illness. In: Material discourses of health and illness. Routledge, 2013: 77-100.

21 Leung E. Improving the medical interpreting services in Hong Kong 2012.

22 Hong Kong Hospital Authority. Annual report on sentinel and serious untoward events: 1 October 2012-30 September 2013; 2014.

23 Griffiths S, Yeoh E. Patient satisfactory survey in Hong Kong Hospita authority 2010 final report School of Public Health and Primary Care and The Chinese University of Hong Kong; 2011. 